\title{
Differences in anterior peripheral pathologic myopia and macular pathologic myopia by age and gender
}

\author{
Cassie A. Ludwig ${ }^{1,2} \cdot$ Nick Boucher $^{3} \cdot$ Namrata Saroj $^{4} \cdot$ Darius M. Moshfeghi $^{1}[$
}

Received: 30 January 2021 / Revised: 17 April 2021 / Accepted: 21 April 2021 / Published online: 21 May 2021

(c) The Author(s) 2021

\section{Key messages}

- Current classification and grading systems for pathological myopia are focused on identifying macular pathologic myopia (MPM) by grading atrophy, traction and neovascularization.

- We discovered demographic differences in a large cohort of patients presenting with anterior peripheral pathologic myopia (APPM) versus MPM

- Male patients are more likely than female patients to present with APPM with a mean age of presentation in the late 40s while female patients are more likely than male patients to present with MPM with a mean age of presentation in the early $60 \mathrm{~s}$

- To aid in biomarker identification, risk stratification, and ultimately prevention strategies, we recommend additional categorization of pathologic myopia into APPM and MPM subgroups

\section{Dear Editor,}

Uncorrected refractive error is the second most common cause of blindness and moderate and severe vision impairment in the world [1]. The etiology of high myopia is multifactorial with both environment and genetics playing a role in axial elongation [2]. Most literature on high myopia focuses on posterior findings such as myopic maculopathy and posterior staphyloma [3]. However, we demonstrated in

Darius M. Moshfeghi

dariusm@stanford.edu

1 Byers Eye Institute, Department of Ophthalmology, Stanford University, 2452 Watson Court, Palo Alto, CA 94303, USA

2 Retina Service, Department of Ophthalmology, Massachusetts Eye and Ear, Harvard Medical School, Boston, MA 02114, USA

3 Vestrum Health, 1121 S. Naper Blvd., Naperville, IL 60540, USA

4 All Eyes Consulting, LLC, 300 East 59th Street 3401, New York, NY 10022, USA a single center that high myopia can be classified into anterior and posterior high myopia, with different risk profiles based on gender and age, suggesting different etiologies for these presentations [4]. We tested these findings in a larger dataset.

Using aggregated de-identified data from the Vestrum Health Database (Naperville, IL, USA), we performed a retrospective study of patients with high myopia enrolled from January 1, 2015 to December 31, 2019. Study participants were identified using ICD-9/ICD-10 codes 360.21/H442. Predetermined ICD diagnoses were then used to classify patients with high myopia into previously described subgroups, with slight modifications for clarity (anterior pathologic myopia, APM, renamed anterior peripheral pathologic myopia, APPM; posterior pathologic myopia, PPM, renamed macular pathologic myopia, MPM) [4]. Subgroups were defined as APPM (lattice degeneration, rhegmatogenous retinal detachment, retinal tear, retinoschisis), MPM (myopic maculopathy, macular hole, staphyloma, angioid streaks, retinal neovascularization, cystoid macular degeneration, exudative retinopathy, retinal pigmented epithelium 
Table 1 Demographics of patients with high myopia and pathologic myopia by anterior and posterior subtypes

\begin{tabular}{cllllll}
\hline Characteristic & $\begin{array}{l}\text { Total population } \\
(\mathrm{N}=1,117,133)\end{array}$ & $\begin{array}{l}\text { APPM } \\
(\mathrm{N}=383,726)\end{array}$ & $\begin{array}{l}\text { MPM } \\
(\mathrm{N}=608,541)\end{array}$ & $\begin{array}{l}\text { CPM } \\
(\mathrm{N}=73,748)\end{array}$ & $\begin{array}{l}\text { IHM } \\
(\mathrm{N}=51,118)\end{array}$ & $p$ value \\
\hline Age, mean $(S D)$ & $55.8(17.2)$ & $47.9(16.9)$ & $63.5(14.2)$ & $58.5(13.6)$ & $57.6(17.3)$ & $<.001$ \\
Age Groups, $n(\%)$ & & & & & \\
$\quad<=35$ & $15,338(14.4)$ & $8,251(26.4)$ & $804(4.4)$ & $780(6.9)$ & $5,503(12.1)$ & $<.001$ \\
$36-45$ & $11,350(10.7)$ & $4,803(15.4)$ & $1,063(5.8)$ & $873(7.7)$ & $4,611(10.1)$ & $<.001$ \\
$46-55$ & $19,889(18.7)$ & $6,699(21.4)$ & $2,527(13.8)$ & $2,283(20.2)$ & $8,380(18.4)$ & $<.001$ \\
$56-65$ & $27,969(26.3)$ & $6,920(22.1)$ & $5,356(29.3)$ & $3,924(34.8)$ & $11,769(25.9)$ & $<.001$ \\
$66-75$ & $19,571(18.4)$ & $3,351(10.7)$ & $5,068(27.8)$ & $2,485(22.0)$ & $8,667(19.1)$ & $<.001$ \\
$76-85$ & $8,737(8.2)$ & $932(3.0)$ & $2,527(13.8)$ & $751(6.7)$ & $4,527(10.0)$ & $<.001$ \\
$>=86$ & $3,191(3.0)$ & $286(0.9)$ & $871(4.8)$ & $178(1.6)$ & $1,856(4.1)$ & $<.001$ \\
Gender, $n(\%)$ & & & & & & \\
Male & $40,039(37.7)$ & $13,015(41.6)$ & $6,088(33.3)$ & $4,798(42.5)$ & $16,138(35.5)$ & $<.001$ \\
Female & $66,204(62.3)$ & $18,235(58.4)$ & $12,173(66.7)$ & $6,479(57.5)$ & $29,317(64.5)$ & $<.001$ \\
\hline
\end{tabular}

$S D$, standard deviation; $A P P M$, anterior peripheral pathologic myopia; $M P M$, macular pathologic myopia; $C P M$, combined pathologic myopia; $I H M$, isolated high myopia detachment, vitreomacular adhesion, epiretinal membrane), combined pathologic myopia (CPM; diagnosis from each of the aforementioned two categories), and isolated high myopia (IHM) [4]. The influence of gender and age on classification were examined using crude bivariate analyses (chisquared, ANOVA, relative risk). Analyses were performed based on individual eye classification. Statistical assumptions were met.

The study population included 54,875 patients $(106,243$ eyes, Table 1). The following subgroups were identified (percentage, mean age at classifying diagnosis): MPM (17.2\%, $63.5 \mathrm{y})$ - accounting for $13.6 \%$ of those $>86 \mathrm{y}$, APPM $(29.4 \%, 47.9$ y) - accounting for $26.9 \%$ of those $<35 \mathrm{y}$, CPM $(10.6 \%, 58.5$ y), IHM (42.8\%, 57.6 y). Females had a $20.9 \%$ greater risk (95\% CI, 17.6 to $24.4 \%$ ) of MPM as compared to males. Males had an $18.0 \%$ greater risk $(95 \%$ CI, 15.8 to $20.3 \%$ ) of APPM as compared to females.

These results align with previous findings of unique subgroups of high myopia with differences in age and gender: (1) MPM patients are more likely to be older females and (2) APPM patients to be younger males, and (3) younger patients are more likely to be diagnosed with APPM while (4) older patients are more likely to have MPM. Differences between males and females are likely driven by a known increased risk of RRD in males [5].

This study is strengthened by its large number of participants. The study was limited by its reliance on ICD coding and lack of refraction data; more myopic refractive error is linked to CPM and MPM as compared to APPM [4].

Herein, we again demonstrate the disparity in populations affected by APPM and MPM based on age and gender. The current ATN grading and classification system does not account for anterior retinal pathology as a disease-defining entity [3]. As anterior retinal pathology is both common and potentially visually significant, it is important to supplement the current system with that suggested herein when classifying and risk-stratifying patients with high myopia, as well as searching for genetic etiologies.

Acknowledgements We would like to acknowledge the insightful contributions of Natalia F. Callaway, MD, MS, and Andrew A. Moshfeghi, $\mathrm{MD}, \mathrm{MBA}$ in the analysis and interpretation of the data herein and critical revisions of this letter.

Funding This work was supported by Research to Prevent Blindness, Inc., NEI P30-EY026877 and the Heed Fellowship awarded through the Society of Heed Fellows to Cassie A. Ludwig, MD, MS.

\section{Declarations}

Conflict of interest Darius M. Moshfeghi has the following conflicts of interest: 1-800 Contacts (board of directors, equity), Akceso Advisors AG (evaluation of DME market), Akebia (scientific advisory board for ROP), Alcon (data safety monitoring board for HAWK/HARRIER), Aldeyra Therapeutics (Site PI: ADX-2191-PVR-001 GUARD), Allegro (scientific advisory board), Apellis (Site PI: APL2-303 DERBY), Bayer Pharma AG (ROP imaging committee), CMEOutfitters.com (CME consultant), Cole Eye Institute (CME consultant), Congruence medical solutions (consultant), dSentz, Inc. (founder, board of directors, equity), Genentech (PROPER grant 2019), Grand Legend Technology, LTD (equity), Iconic Therapeutics (steering committee, unpaid), Irenix (scientific advisory board, unpaid), Linc (founder, equity, board of directors), Northwell Health (grand rounds), Novartis Pharmaceuticals (data safety monitoring board for HAWK/HARRIER, KITE/KESTREL, China nAMD/DME, pediatric advisory board), Ocular Surgery News (consultant), Pr3vent (founder, board of directors, equity), Praxis UNS, Inc. (consultant), Prime Medical Education (CME consultant), Promisight, Inc. (founder, board of directors, equity), Pykus (scientific advisory board, equity), Regeneron (CME consultant, ROP steering committee, PI for ROP trial), Retina Technologies LLC (advisor, consultant), Retina Today/Pentavision (consultant), Shapiro Law Group (ROP expert witness), SLACK, Inc. (CME consultant), University of Miami (CME consultant), VersI, Inc. 
(founder, equity), Vindico (CME consultant), Visunex (scientific advisory board, equity.

Namrataa Saroj has the following conflicts of interest: Apellis (Consultant); Allegro (Consultant, equity); Amgen (Consultant); iRenix (Consultant, equity); RegenxBio (Consultant); SamaCare (Consultant, equity); Pr3vent (Equity).

Open Access This article is licensed under a Creative Commons Attribution 4.0 International License, which permits use, sharing, adaptation, distribution and reproduction in any medium or format, as long as you give appropriate credit to the original author(s) and the source, provide a link to the Creative Commons licence, and indicate if changes were made. The images or other third party material in this article are included in the article's Creative Commons licence, unless indicated otherwise in a credit line to the material. If material is not included in the article's Creative Commons licence and your intended use is not permitted by statutory regulation or exceeds the permitted use, you will need to obtain permission directly from the copyright holder. To view a copy of this licence, visit http://creativecommons.org/licenses/by/4.0/.

\section{References}

1. Bourne RRA, Stevens GA, White RA et al (2013) Causes of vision loss worldwide, 1990-2010: a systematic analysis. Lancet Glob
Health 1:e339-349. https://doi.org/10.1016/S2214-109X(13) 70113-X

2. Chakraborty R, Read SA, Vincent SJ (2020) Understanding Myopia: Pathogenesis and Mechanisms. In: Ang M, Wong TY (eds) Updates on Myopia: A Clinical Perspective. Singapore: Springer, pp 65-94

3. Ruiz-Medrano J, Flores-Moreno I, Ohno-Matsui K et al (2020) Validation of the recently developed ATN classification and grading system for myopic maculopathy. Retina 40(11):2113-2118. https://doi.org/10.1097/IAE.0000000000002725

4. Ludwig CA, Shields RA, Chen TA et al (2018) A novel classification of high myopia into anterior and posterior pathologic subtypes. Graefes Arch Clin Exp Ophthalmol 256:1847-1856. https://doi.org/10.1007/s00417-018-4071-0

5. Sheu S-J, Ger L-P, Chen J-F (2007) Male sex as a risk factor for pseudophakic retinal detachment after cataract extraction in Taiwanese adults. Ophthalmology 114:1898-1903. https://doi.org/ 10.1016/j.ophtha.2007.02.030

Publisher's note Springer Nature remains neutral with regard to jurisdictional claims in published maps and institutional affiliations. 